\title{
Guerra, historicismo e direito
}

War, Historicism and Law

\author{
Marco Antonio Silveira \\ Doutor em História Social pela \\ Universidade de São Paulo (FFLCH/ \\ USP - São Paulo/Brasil) e professor \\ adjunto no Departamento de \\ História da Universidade Federal de \\ Ouro Preto (ICHS/UFOP - Mariana/ \\ Brasil) \\ e-mail: \\ mantoniosilveira@yahoo.com.br
}

\section{Resumo}

Este breve artigo visa questionar em que medida os discursos sobre a guerra das raças, descritos por Clément Thibaud em "La ley y la sangre", embora retomem elementos do historicismo, não reproduzem as estratégias de modelos historiográficos voltados à subordinação da guerra à soberania.

\section{Abstract}

This short paper aims at questioning the extent in the which the discourses about the war of races described by Clément Thibaud en "La ley y la sangre", although retaking elements from historicism, reproduce the strategies of historiographical patterns that intend to subordinate the war to the sovereingty.

\section{Palavras-chave}

guerra, historiografia, vocabulário político, Independência, América Espanhola

\section{Keywords}

war, historiography, political vocabulary, Independence, Spanish America 
1

THIBAUD, Clément. La ley y la sangre. La "guerra de razas" y la constitución en la América Bolivariana. Almanack, Guarulhos, n.01, p.5-23, $1{ }^{\circ}$ semestre de 2011.

2 FOUCAULT, Michel. Em defesa da sociedade. São Paulo: Martins Fontes, 1999.
Para o leitor brasileiro, o artigo que Clément Thibaud nos apresenta merece destaque por diversas razões, a mais importante delas referindose à própria abordagem que o fundamenta ${ }^{1}$. A retomada da perspectiva foucaultiana, particularmente aquela exposta no livro Em defesa da sociedade, encontra a historiografia num momento particular em que modelos explicativos de matriz jurídica se tornaram decisivos ${ }^{2}$. Nesse sentido, a apropriação que Thibaud faz do conceito de guerra abre espaço para uma atitude mais crítica em relação aos vínculos entre discurso soberano e discurso historiográfico.

Do que se trata quando são referidos discursos de matriz jurídica ou elementos do discurso soberano? Colocando o problema de maneira simples, trata-se do uso de modelos de análise e de investigação que os historiadores têm partilhado, especialmente desde a metade do século $\mathrm{XVIII}$, com as ciências sociais e com os agentes preocupados em afirmar a soberania do Estado. Em outras palavras, trata-se de modelos explicativos que, de uma maneira ou de outra, articulam sistematicamente as complexas relações entre população, comportamento, território, mercado e instituições estatais. Evidentemente, o uso de categorias e de modelos de matriz jurídica por parte dos historiadores não implica sempre sua adesão ao discurso soberano. Também não significa necessariamente a dissolução dos conflitos sociais em explicações que reproduziriam tautologicamente a ordem - nesse caso, como entender o pensamento liberal ou o pensamento marxista? Faz-se necessário, contudo, reforçar a idéia de que os discursos historiográficos devem muito às tentativas de explicar, e por vezes justificar, a existência e a constituição do Estado, cabendo aqui a lembrança de que parte expressiva das fontes com que trabalham os historiadores foi produzida por instituições estatais. Assim sendo, considerações teórico-metodológicas calcadas no conceito de guerra convidam, numa apropriação mais radical, à elaboração de modos alternativos de escrita historiográfica.

A crítica inicial proposta por Thibaud - dedicada à constatação de que a guerra tem sido vista como "fator secundário" porque ligada à "historiografia acadêmica tradicional" - nos impele a refletir sobre um problema decisivo: visto que a guerra, doutrinária e historiograficamente, tem sido submetida ao discurso soberano, como liberar suas amarras e torná-la conceito-chave na elaboração de outros modelos de escrita da história? 0 texto de Thibaud apresenta alternativas ao investigar os vínculos entre a noção de guerra de raças e o historicismo. Porém, desse ponto partem três problemas marcantes. 0 primeiro nos leva a questionar em que medida a própria perspectiva descrita por Thibaud, referente à Venezuela e à Colômbia das décadas de 1810 e 1820, não implica um modelo explicativo que, ao fim e ao cabo, termina também por subordinar a guerra e o historicismo ao direito. 0 segundo indaga se o uso do conceito de guerra não deve nos conduzir à releitura de autores da Antiguidade. 0 terceiro problema, enfim, significa avaliar se, para além do estudo da apropriação do vocabulário historicista e bélico por parte de agentes sociais - operação muito bem reconstituída por Thibaud -, o conceito de guerra não é válido ainda como fundamento de paradigmas historiográficos que dizem algo importante sobre as sociedades colonias.

0 segundo e o terceiro pontos remetem, pelo menos em parte, à crise do marxismo. Em certa medida, o questionamento à dimensão teleológica e materialista do marxismo esvaziou parte das leituras voltadas 
ARENDT, Hannah. Da revolução. São Paulo: Ártica, 1988.

4

Idem. Entre o passado e o futuro. São Paulo: Perspectiva, 1972, em particular o capítulo "Que é autoridade" à compreensão da guerra social, cedendo espaço a interpretações que privilegiam os instrumentos de paz gerados pela presença das instituições estatais, pelo parentesco e pelos costumes. Esse movimento, por vezes, fez parecer que o tratamento historiográfico de sociedades da Idade Moderna através do paradigma bélico teria se tornado anacrônico, uma vez que tais sociedades seriam reguladas por doutrinas aristotélicas, tomistas e escolásticas. Sem que se possa aprofundar o tema pelo momento, vale mencionar que o conhecimento que Marx possuía da Antiguidade e a presença do problema da guerra em autores escolásticos como Francisco Suárez sugerem que a guerra pode ser retomada pela historiografia como um paradigma historiográfico que nada tem de anacrônico. A questão aqui seria avaliar a validade da elaboração de discursos historiográficos de matriz bélica que se recusam a submeter-se ao direito e à soberania. Esse é um problema que aparece formulado na Grécia Clássica e em Roma: se Platão e Aristóteles submeteram o interesse pessoal à metafísica do bem comum, o corpo à alma, também deixaram uma reflexão decisiva sobre os limites das formas de governo, retomada mais adiante por pensadores como Maquiavel e Montesquieu.

Chega-se, então, ao primeiro ponto levantado acima: se os discursos referidos por Thibaud, embora perpassados pelo historicismo, não acabam se dissolvendo no direito e na soberania. Quais seriam as características do regime de historicidade apontado por Foucault? A "violência original", a "neutralidade axiológica" e a compreensão da sociedade como embate de forças são elementos decisivos. Contudo, parece que seu aspecto crucial consiste na idéia de que, sendo o direito instrumento dos fracos contra os fortes, a sociedade consistiria essencialmente numa correlação de forças radicada na natureza, cujo resultado, também natural, seria o domínio dos últimos sobre os primeiros. É por isso que, para Foucault, Thomas Hobbes não pode ser identificado ao discurso historicista do conde de Boulainvilliers: embora descreva o estado de natureza como a guerra de todos contra todos, Hobbes pretende, por fim, submeter a guerra ao direito.

Assim, os exemplos citados por Thibaud no decorrer do artigo suscitam algumas dúvidas acerca da identificação destes com a abordagem historicista descrita por Foucault. Partindo do pressuposto de que as noções de violência original e de guerra podem ser também operadas num discurso de matriz jurídica - como fazem, em perspectivas distintas, Hobbes e o mencionado Francisco Suárez -, talvez seja excessivo falar de uma aproximação propriamente historicista no contexto analisado por Thibaud. Nos ditos de Lorenzo de Villanueva e de Miguel de Pombo, por exemplo, o uso de palavras como consentimento, contrato do povo, despotismo e regeneração parece remeter ao vocabulário escolástico. É interessante observar, acerca do último termo, o que afirma Hannah Arendt a respeito da Independência dos Estados Unidos ${ }^{3}$ : os revolucionários norteamericanos conceberam-se inicialmente como regeneradores, adotando a experiência romana e seu modelo soberano como referência para a fundação republicana. No mesmo sentido, destaque-se que, como sugere a mesma autora, a questão decisiva para os revolucionários da América do Norte era fundar a república na autoridade ${ }^{4}$. Apesar de algumas diferenças históricas, a Revolução Francesa também lidou com as mesmas questões.

Dessa forma, o constitucionalismo, especialmente quando baseado nos exemplos norte-americano e francês, tende a resolver o problema da guerra dissolvendo-a numa releitura de concepções autoritárias e 
jurídicas. Talvez seja essa a perspectiva do fiscal da Audiência de Caracas em 1808, mencionado por Clément Thibaud - perspectiva que se distancia do paradigma bélico descrito por Foucault, cujos desdobramentos levarão, por exemplo, a Nietzsche. Os discursos sobre a "guerra a muerte", com suas referências à "pátria primitiva", são os que mais se aproximam da vertente historicista. Mas, mesmo nesse caso, não deixa de ser surpreendente a distinção feita por Bolivar entre guerra de libertação e instauração do novo pacto social. 0 argumento utilizado por ele não é o do natural, e por isso legítimo, domínio de uma raça sobre a outra, mas o da validade da suspensão temporária do direito das gentes em prol de uma guerra justa e discriminatória que deve ser combatida em defesa dos direitos naturais do Homem. Há aqui, portanto, clara oposição entre uma vertente historicista, que vê o domínio violento como algo natural, e uma vertente jurídica, que o concebe como agressão a direitos estabelecidos pela natureza. Embora ambas possuam um fundo comum, implicam concepções opostas de natureza. 0 que isso significa? Significa que, sendo intensa a percepção da crise de autoridade na era das revoluções, independentistas e republicanos procuram solucioná-la fincando a autoridade na natureza. Como os revolucionários norte-americanos e franceses perceberam, porém, essa saída era simples demais para dar certo.

Para finalizar, um comentário sobre os pardos. É muito interessante a análise de Thibaud sobre os esforços visando, através de sua integração, evitar-se a guerra civil. Mais uma vez, o que parece operar aqui é mais um discurso jurídico do que historicista. Mas fica uma pergunta que interessa de perto à historiografia brasileira: por que para a "pardocracia" o antigo modelo, baseado na mediação dos agentes reais, parecia mais adequado e integrador que o modelo de matriz liberal? 